\title{
Containing risk
}

\author{
The ad-hoc proliferation of high-security biological labs must be controlled, and should be tied in more \\ closely to broader research and public-health goals.
}

$\Lambda$ $t$ the heart of any effort to control proliferation or improve safety, whether it concerns plutonium, toxic chemicals, disease agents or anything else, is the ability to take an inventory - to know with some confidence just how much material exists and where it is being kept. So it's disturbing to realize that authorities in many parts of the world often have only the vaguest notion of how many high-level biosecurity facilities exist on their territory, and that so few of them can document what stocks of deadly biological pathogens such facilities hold and exchange.

These labs have multiplied over the past decade as a consequence of concerns about bioterrorism following the terrorist attacks of 11 September 2001, and the appearance of public-health threats such as SARS and avian flu. New construction is already set to boost the number of biosafety-level-4 (BSL-4) labs in the European Union (EU) from 6 to 15 or more, and that in the United States from 7 to 13. BSL-4 is the highest level on the World Health Organization's rating scheme, and is required for labs that work with deadly, highly contagious pathogens, such as Ebola, Marburg, Nipah or Lassa viruses, for which no treatment exists.

Meanwhile, a September report by the US General Accounting Office (www.gao.gov/new.items/d09574.pdf) estimates that the number of American BSL-3 facilities has more than trebled, from around 415 in 2004 to 1,362 last year, But the report emphasizes the uncertainties. "The universe of BSL- 3 and -4 laboratories is unknown," it states. "[T] here are likely other laboratories that we were unable to identify." Stocktaking in Europe is no better.

Building adequate high-containment infrastructure is important, in the sense that high-containment labs are essential for understanding exotic viruses, analysing samples from outbreaks and researching therapeutics and vaccines (see page 154). But the uncontrolled and uncoordinated nature of the growth of such facilities is problematic. Multiple agencies, countries and institutions too often pursue their own agendas, building biosecurity facilities with insufficient consideration for one another's plans or asking whether so much overall new lab capacity is needed - especially given the attendant risks of proliferation, accidental human infections and lab escapes.

The relevant authorities should undertake a much broader evaluation of such questions across institutions, focusing on how many and what sort of facilities are needed, if any at all; where they should be located; and how they could be coordinated to best suit the goals of broader research and some sort of overarching oversight structure is sound."
"The logic of having public-health agendas. In the EU, for example, BSL-4 labs are currently concentrated in western and northern Europe. But they are lacking in southern and eastern Europe, where the BSL-4 class Crimean-Congo haemorrhagic fever virus is endemic.

Fortunately, such evaluation seems to be getting on the agenda. The EU has created a pilot for a proposed EU-wide network, the 'European research infrastructure on highly pathogenic agents' (ERINHA), which seeks to better coordinate the construction and operation of BSL-4 labs (see page 146). This is a step in the right direction, and should be complemented by a similar initiative for Europe's BSL-3 labs. Meanwhile, the General Accounting Office report recommends that the National Security Advisor, in consultation with federal agencies, designate a single body to evaluate all US high-containment labs. This recommendation should be taken forward.

In both cases, the logic of having some sort of overarching oversight structure is sound. Such structures could also provide much-needed mechanisms for the sharing of best safety and security practices and experience. Excessive oversight is undesirable. But the uncontrolled growth of labs, and the spate of instances of lax security in the United States in recent years (see Nature 461, 577; 2009), indicate the need for greater independent oversight, and less laissez-faire.

\section{No turning back}

\section{Spain should not use the recession as an excuse to stall plans to boost its scientific enterprise.}

\footnotetext{
T
} he past two decades have seen Spain transform itself from a scientific backwater into an internationally respected player in the research world. Much of that progress has occurred since the Socialist Party swept to power in 2004, pledging to turn Spain into an innovation economy (see Nature 451, 1029; 2008).

During the Socialists' first term in office, for example, they doubled the science budget to just over $€ 8$ billion (US $\$ 12$ billion), pushing it above $1.1 \%$ of the country's gross domestic product (GDP) and much closer to the European Union average of $1.8 \%$ of GDP. The party was re-elected in 2008, having pledged to cut bureaucracy and push funding for research to a target of $2 \%$ of GDP. Almost immediately it set up the Ministry of Science and Innovation, finally extracting science from under the purview of the education ministry. Cristina Garmendia, a molecular biologist who has founded several successful biotechnology companies, was appointed as head of the new ministry.

Since then, however, the momentum has been lost. Garmendia's political inexperience has shown. She was slow to build up a functioning ministry, and has not developed the necessary political clout to convince the government, now grappling with the global recession, to stick to its vision for science.

Granted, the government has bolstered financial support for the country's budding biotechnology and other high-tech industries. But 